\section{O campo Saúde do Trabalhador: resgatando conhecimentos e práticas sobre as relações trabalho-saúde}

\author{
The Workers' Health field: reclaiming knowledge \\ and practices in the interface between work \\ and health
}

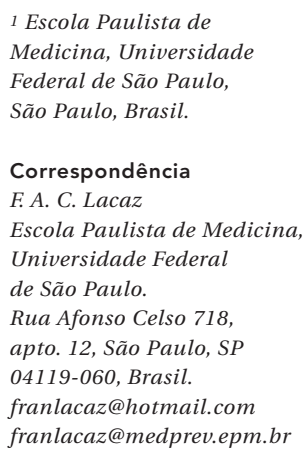

\begin{abstract}
This article discusses the underlying theoretical and operational premises in the fields of workers' health and occupational health, highlighting their respective frameworks and epistemological differences, based on Foucaultian archeology. The theme is particularly relevant, due to: the apparently limited attention to interdisciplinary research approaches in workers' health; various setbacks in public health measures at the social policy level; related weaknesses in the Brazilian trade union movement; and the conceptual misinterpretations drafted into the final report of the 3rd National Workers' Health Conference in November, 2005, convened by the Ministries of Social Security, Health, and Labor. The event resulted from the Workers' Health Conferences held in various States and Municipalities, mobilizing some 100,000 activists throughout Brazil and electing the delegates to the 3 rd $\mathrm{Na}$ tional Conference.
\end{abstract}

Occupational Health; Occupational Health Policy; Health Knowledge, Attitudes, Practice

\section{Bases teórico-metodológicas do campo Saúde do Trabalhador}

A abordagem das relações trabalho-saúde tem experimentado retrocesso que pode ser observado quanto à sua apreensão, em termos disciplinares, adotada nas pesquisas 1,2; à involução que caracteriza a proposta programática 3 a qual privilegia o assistencialismo nas ações da rede de saúde do Sistema Único de Saúde (SUS) 4; ao que se soma a fragilidade do movimento sindical 5 . As resoluções da 3ạ Conferência Nacional de Saúde do Trabalhador, realizada em novembro de 2005 6, expressam essa situação, o que ensejou este artigo, na busca do resgate das formulações do campo Saúde do Trabalhador, elaboradas e amadurecidas nos anos 1970-1980 7. Nesses anos consubstanciam-se, a partir desse campo, conhecimentos e práticas que, cotejadas com a abordagem da Saúde Ocupacional, mostram seu reducionismo e simplismo. Frise-se que aquele campo incorporava abordagens desenvolvidas pelas ciências sociais 8,9; considerando contribuição da Medicina Social Latino-Americana e da Saúde Coletiva 7,10,11,12,13.

Assim, aqui se assume que Saúde do Trabalhador é campo de práticas e conhecimentos cujo enfoque teórico-metodológico, no Brasil, emerge da Saúde Coletiva, buscando conhecer (e intervir) (n)as relações trabalho e saúde-doença, tendo como referência central o surgimento de um novo ator social: a classe operária industrial, 
numa sociedade que vive profundas mudanças políticas, econômicas, sociais. Ao contrapor-se aos conhecimentos e práticas da Saúde Ocupacional, objetiva superá-los, identificando-se a partir de conceitos originários de um feixe de discursos dispersos formulados pela Medicina Social Latino-Americana, relativos à determinação social do processo saúde-doença; pela Saúde Pública em sua vertente programática e pela Saúde Coletiva ao abordar o sofrer, adoecer, morrer das classes e grupos sociais inseridos em processos produtivos 7,13 .

Metodologicamente, é na Arqueologia de Foucault 14 que se busca elementos para compreender o campo, dèmarche que envolve enunciados, normas, conceitos, conformando saberes (e práticas) que postulam estatuto de cientificidade. Segundo Foucault 15 (p. 12): "Cada sociedade tem seu regime de verdade, sua 'política geral' de verdade: (...) os tipos de discurso que ela acolhe e faz funcionar como verdadeiros; os mecanismos e as instâncias que permitem distinguir os enunciados verdadeiros dos falsos, a maneira como se sancionam uns e outros; as técnicas e os procedimentos que são valorizados para a obtenção da verdade; o estatuto daqueles que têm o encargo de dizer o que funciona como verdadeiro".

Tomando também como referência Foucault, pode-se apreender o campo de relações para além da Arqueologia, o que exige revolver o terreno dos sistemas de conhecimento engendrados e acoplados a modalidades de poder, através da Genealogia, quando: “... desloca-se a problemática do saber para o poder. (...) a problemática do saber não é abandonada, todavia o foco se dirige para o regime político de produção da verdade. Sob a perspectiva do método genealógico Foucault aponta (...) uma nova analítica do poder que enfatiza suas táticas e estratégias e cuja pertinência não diz respeito à matriz ordem/obediência política, porém aos processos de assujeitamento, ou seja, à constituição de sujeitos assujeitados" 16 (p. viii, grifo nosso).

Trata-se, ainda, de constatar a eficácia política de um discurso contra-hegemônico que, ao produzir conhecimentos e práticas compartilhados com os dominados, visa a elevar sua consciência sanitária, rompendo com uma rede de relações de poder, que não se situa apenas nos aparelhos de Estado, mas que perpassa os interesses dos sujeitos nas práticas discursivas e que “... não pode ser mais compreendida como totalidade articulada e abstrata, produto da progressiva racionalização das práticas e das representações sociais. A sociedade somente pode ser visualizada em seu operar concreto, na imensa e complexa rede (...) que imbrica instituições aparentemente tão díspares como a (...) o hospital, (...) a fábrica, a escola, a prisão e institui laços entre o educador, o médico, o jurista, o carcereiro ...” 16 (p. ix).

E, relações de poder conformam a Saúde Ocupacional o que, de formas diferenciadas contribui para a alienação e desinformação do trabalhador, conferindo maior capacidade de controle do capital sobre o trabalho, alienação esta derivada da informação restrita e da atuação autoritária dos profissionais de saúde no trabalho ou fora dele 13. Para superar tal realidade, busca-se que enunciados, pressupostos, normas, regras, instituições e sujeitos constroem e compõem o campo contra-hegemônico Saúde do Trabalhador.

A configuração do campo Saúde do Trabalhador constitui-se por três vetores: a produção acadêmica; a programação em saúde na rede pública e; o movimento dos trabalhadores, particularmente a partir dos 1980 7, quando seu discurso assume caráter mais propositivo junto ao Estado, ao “... vislumbrar a possibilidade das classes trabalhadoras influírem mais decididamente na esfera política, deixando de dizer apenas não, para também indicarem soluções para os problemas sociais, políticos e econômicos" 17 (p. 120).

Consubstancia-se, assim, um campo em construção, que se identifica por referência à Saúde Ocupacional, abordagem esta que incorpora práticas e conhecimentos da clínica, medicina preventiva e epidemiologia clássica, mediante a história natural da doença para a análise das doenças e acidentes do trabalho mediante a tríade "agente-hospedeiro-ambiente", conforme proposto em 1950 pelo Comitê Misto de Peritos da Organização Internacional do Trabalho (OIT)/ Organização Mundial da Saúde (OMS) 18.

Considera-se, então, que ao cotejar o discurso da Saúde Ocupacional e da Saúde do Trabalhador, que se propõe interdisciplinar, multiprofissional, aberto à participação inclusive do ponto de vista metodológico ${ }^{19}$, poder-se-á identificar suas "verdades" e as condições de possibilidade de sua emergência, verificando como sua formação e prática discursivas consolidam-se, relacionado-as com as práticas extradiscursivas 14,20.

Assim, amplia-se o enfoque, na busca de instrumental que privilegie medidas de prevenção e que, ao incorporar o conhecimento dos trabalhadores, potencialize lutas pela melhoria das condições de trabalho e defesa da saúde 7 .

Nessa empreitada aparecem conflitos e contradições claras de interesse, o que exige que se estabelaçam hierarquias e determinações. $\mathrm{O}$ aprofundamento dessa questão acopla-se a análises histórico-sociais que permitam captar seu dinamismo dialético 21 , pois as relações trabalho-saúde situam-se no entrecruzamento dos desígnios do capital com as possibilidades 
de transformação social, através da luta política assumida pelo pólo trabalho em sociedades concretas.

\section{Enunciados, conceitos, normas e regras da Saúde Ocupacional e do campo Saúde do Trabalhador}

Para Mendes 18, é da Medicina Preventiva que emergem bases para enunciação da Saúde Ocupacional pela OIT/OMS, ao usar termos como prevenção, proteção, riscos, adaptação, visando a intervir na saúde dos trabalhadores. E, o paradigma da causalidade dos agravos à saúde dáse pela precedência das condições de trabalho, numa visão a-histórica e descontextualizada das relações econômicas, polítco-ideológicas e sociais que influem nos nexos entre trabalho e saúde-doença ?.

Conforme Arouca 21, a universalidade dos conceitos estabelece-se quando, ao serem elaborados por grupo de experts institucionais - aqui vinculados à OIT/OMS - produzem um discurso impermeável às várias possibilidades de se pensar, no caso, as relações trabalho e saúde-doença, o qual assume duplo caráter: é estruturado e estruturante. Estruturado porque é um determinado grupo que o formula, definindo um leque de respostas possíveis. Estruturante porque limita a eventualidade de se discutir, por exemplo, a eficácia e os limites da Saúde Ocupacional. E, tais limites conceituais constrangem a capacidade interpretativa da realidade. A abordagem das relações trabalho e saúde-doença parte da idéia cartesiana do corpo como máquina, o qual expõe-se a agentes/fatores de risco. Assim, as conseqüências do trabalho para a saúde são resultado da interação do corpo (hospedeiro) com agentes/fatores (físicos, químicos, biológicos, mecânicos), existentes no meio (ambiente) de trabalho, que mantêm uma relação de externalidade aos trabalhadores. $\mathrm{O}$ trabalho é apreendido pelas características empiricamente detectáveis mediante instrumentos das ciências físicas e biológicas. Aqui os "limites de tolerância" e "limites biológicos de exposição”, emprestados da higiene industrial e toxicologia, balizam a intervenção na realidade laboral, buscando "adaptar" ambiente e condições de trabalho a parâmetros preconizados para a média dos trabalhadores normais quanto à suscetibilidade individual aos agentes/fatores. Em conseqüência dessa compreensão, o controle da saúde preconizado pela Saúde Ocupacional resume-se à estratégia de adequar o ambiente de trabalho ao homem e cada homem ao seu trabalho 18. Daí deriva a importância dos exames admissionais e periódicos, realizados pelos Ser- viços Especializados de Medicina do Trabalho (SEMT) das empresas, na busca para selecionar os mais hígidos, excluindo aqueles que apresentem algum "desvio" da normalidade ?

Os limites epistemológicos dessa abordagem fazem com que à Saúde Ocupacional escape possibilidade de considerar e apreender outras relações, como aquelas configuradas pela organização-divisão do trabalho: o ritmo; a duração da jornada; o trabalho em turnos; a hierarquia; a fragmentação/conteúdo das tarefas; o controle da produtividade, cujas conseqüências para a saúde expressam-se como doenças crônico-degenerativas e distúrbios mentais dos coletivos de trabalhadores 22. Nesse contexto, a Saúde Ocupacional pouco tem para contribuir, já que atua sobre indivíduos, privilegiando o diagnóstico e o tratamento dos problemas de natureza orgânica, a partir da visão empirista e positivista trazida da clínica. Aqui caberá pouco espaço para a subjetividade do trabalhador, tomado como paciente e objeto da técnica, estreitando a possibilidade de apreensão das formas de adoecimento no trabalho na contemporaneidade, cuja causalidade cada vez mais complexa, envolve a organização do trabalho e sua relação com a subjetividade dos coletivos de trabalhadores 23 .

Tal limite epistemológico impede que a Saúde Ocupacional considere e opere sobre nexos mais complexos, pouco contribuindo na compreensão da causalidade das doenças relacionadas ao trabalho, especialmente as cárdio-vasculares, psicossomáticas e mentais, características do adoecimento pelo trabalho hoje ?

Maneira diversa de compreender as relações trabalho e saúde-doença é introduzida pela análise da determinação social do processo saúdedoença, privilegiando o trabalho. A Medicina Social Latino-Americana apreende-o através do processo de trabalho, categoria explicativa que se inscreve nas relações sociais de produção estabelecidas entre capital e trabalho. E, conforme a acepção marxista, aqui o trabalho é, ontologicamente, a ação do homem sobre a natureza para modificá-la e transformá-la e a si mesmo não sendo, portanto, externa ao homem ${ }^{24}$. Tal ação vai ocorrer sobre o objeto de trabalho, mediante os instrumentos de trabalho, configurando o próprio trabalho e suas diferentes formas de organização, divisão, valorização, características de cada formação social e modo de produção, o que imprime um caráter histórico ao estudo das relações trabalho-saúde e, conseqüentemente, do adoecimento pelo trabalho 25 .

Importa, então, desvendar a nocividade do processo de trabalho sob o capitalismo e suas implicações: alienação; sobrecarga e/ou subcarga; pela interação dinâmica de "cargas" sobre os 
corpos que trabalham, conformando um nexo biopsíquico que expressa o desgaste impeditivo da fluição das potencialidades e da criatividade. A abordagem em Saúde do Trabalhador busca resgatar o lado humano do trabalho e sua capacidade protetora de agravos à saúde dos trabalhadores, tais como mal-estares, incômodos, desgastes, para além dos acidentes e doenças 12 .

$\mathrm{Na}$ medida em que as classes trabalhadoras constituem-se em novo sujeito político e social, conforme sugere o campo Saúde do Trabalhador, este incorpora idéia de trabalhador que difere frontalmente da anterior: passiva, como hospedeiro ou paciente; apreendendo-o como agente de mudanças, com saberes e vivências sobre seu trabalho, compartilhadas coletivamente e, como ator histórico, ele pode intervir e transformar a realidade de trabalho, participando do controle da nocividade; da definição consensual de prioridades de intervenção e da elaboração de estratégias transformadoras 19.

Tambellini et al. 13 trazem elementos para pensar a epistemologia do campo quando discutem as relações trabalho-saúde em abstrato, pela elaboração de grupo multiprofissional de investigadores (da saúde, ciências sociais, filosofia), cujo objeto - as relações capital/trabalho; trabalho/saúde; sociedade/classes/saúde - constrói-se mediante abordagem teórico-conceitual e análise inter(trans)disciplinar. Os produtos do conhecimento científico derivado dessa abordagem e suas consequências para a saúde contribuem para a elaboração de políticas públicas; ao lado da formulação teórica que permite maiores níveis de consciência política, bem como novas modalidades de organização do saber, podendo subsidiar ações sociais abrangentes em saúde, mediante prática-teórica cujos agentes são equipes de técnicos, trabalhadores e profissionais da saúde que buscam colocar a técnica a serviço do pólo trabalho. A investigação em Saúde do Trabalhador parte das classes, frações de classes e grupos de trabalhadores organizados política e economicamente, adotando como instrumentos elementos da Saúde Coletiva, da clínica, da epidemiologia aos quais agregam-se ferramentas do planejamento, política, economia etc., visando à prevenção e buscando manter os determinantes da saúde sob controle dos trabalhadores, ao objetivar a defesa de sua saúde, mediante construção do conhecimento da realidade mais integrado e participativo. Para aqueles autores, o estudo das relações trabalho e saúde e a conscientização pela informação compartilhada permitem atuação democrática no sistema de saúde dos profissionais de saúde e dos trabalhadores.

\section{Os discursos sobre trabalho e saúde no Brasil nos anos 1970-1980 e na atualidade}

Nos anos 1950-1960, o industrialismo desenvolvimentista sustenta a estratégia de organização dos serviços médicos nas empresas que, ao lado de fazerem atendimento clínico-individual, assumem atribuição prescrita pela Saúde Ocupacional, atuando no estudo das causas de absentismo, na seleção de pessoal e análise das doenças e acidentes ocupacionais: “... existe um papel importante, do ponto de vista dos empresários, a ser desenvolivdo por uma seção médica no interior das empresas..." 26 (p. 181-2).

Quanto à ação governamental, o discurso da técnica articulado às relações de poder e ao disciplinamento 27 do trabalhador, embasado em teorias científicas universais institucionaliza-se nacionalmente nos anos 1970, mediante política adotada pelo Regime Militar que obriga a criação dos Serviços Especializados em Engenharia de Segurança e Medicina do Trabalho, delegando às empresas a tutela da saúde dos trabalhadores 7. Tal política visa a aumentar a produtividade e a saúde tem caráter de razão instrumental para a produção. Essa é a base da atuação do Estado, através do setor trabalho 7 .

Ainda na década de 1970, completam-se as transformações sócio-econômicas, políticas e culturais na América Latina no que concerne à industrialização e à urbanização ${ }^{8}$.

Nessa época são publicados importantes estudos sobre as relações trabalho-saúde. Constituem referências para entendê-las, os textos de Laurell 28 e Tambellini 10 relativos aos contextos sócio-econômicos do México e do Brasil.

Mais ainda, na América Latina, nos 1970, a emergência dessa formulação teórico-conceitual acompanha-se de nova visão sanitária. Tratavase de retornar ao social para apreender a determinação dos agravos à saúde dos trabalhadores, incorporando categorias do marxismo, conforme elaboração teórico-metodológica de autores "filiados" à Medicina Social Latino-Americana e à Saúde Coletiva 7 .

Uma articulação bastante ampla dos saberes de filósofos e cientistas sociais, de políticos, planejadores, de profissionais de saúde, com os dos trabalhadores organizados em seus órgãos de representação, sustenta a luta pela transformação da organização dos processos de trabalho, visando a resgatar o real ethos do trabalho: libertário e emancipador 29.

O quadro de deterioração das condições de vida e degradação do trabalho conseqüentes da industrialização tardia e seus reflexos sobre a saúde expressa-se na ocorrência cada vez maior de acidentes do trabalho 10 . 
Assim, a Saúde do Trabalhador informada pela Medicina Social Latino-Americana enquanto campo de estudos e seu desenvolvimento, associam-se ao processo de industrialização e à forma particular por este assumida na América Latina. Destaque-se sua rapidez, a grande heterogeneidade de processos de trabalho concretos dentro da nova divisão internacional do trabalho; o caráter efêmero dos milagres econômicos vividos por países como a Argentina, Brasil, Chile, México e as profundas mudanças na estrutura de classes, com o surgimento da jovem classe operária industrial urbana 30 . Ao emergir constitui-se num “... novo sujeito social e político, que tem como experiência vivencial direta a concretização das contradições que caracterizam o desenvolvimento industrial tardio" 8 (p. 256). Por isso, assume reivindicações já conquistadas pela classe operária dos países capitalistas centrais. O traço marcante dessa industrialização, quando visto pelo lado dos trabalhadores, envolve uma ruptura com formas passadas de produzir e viver, sendo hegemonizado pela grande indústria multinacional de bens de consumo duráveis e pela urbanização, associados à extrema expoliação da força de trabalho, possível em função do exército industrial de reserva e de ações repressivas 30 . Os trabalhadores lutam, ainda, pela regulamentação da jornada de trabalho e salário e, sincronicamente, defendem sua saúde e integridade física buscando a melhoria das condições de trabalho ${ }^{8}$.

Os anos 1980 trazem significativa mudança de rumos na política de saúde brasileira, quando, na VIII Conferência Nacional de Saúde, em 1986, consolida-se a proposta de criação do SUS com atributo de coordenar as ações de saúde, agora alçada à condição de direito social e de cidadania, ações estas que englobam, como tendência mundial, a saúde dos que trabalham 31 .

Ainda no início dos anos 1980, em São Paulo, setores do movimento sindical, como metalúrgicos, químicos, petroquímicos, bancários, exigem dos serviços de saúde pública envolvimento com as questões de saúde relacionadas ao trabalho, fato contemporâneo à criação, por parte de dezenas de sindicatos de trabalhadores, do Departamento Intersindical de Estudos e Pesquisas de Saúde e dos Ambientes de Trabalho (DIESAT), que terá importante papel na discussão sobre o rompimento com o assistencialismo médico existente dentro dos sindicatos, nefasta herança dos tempos do Estado Novo, numa perspectiva de superá-lo, propondo que tal atribuição seja da rede pública de saúde 7 . A assessoria técnica do DIESAT junto ao Sindicato dos Trabalhadores Químicos e Petroquímicos do ABCD teve relevante papel na superação do assistencialismo, contribuindo para que o sindicato propusesse, no ano de 1984, à Secretaria de Estado da Saúde (SES), o Programa de Saúde do Trabalhador Químico do $\mathrm{ABC}$, experiência pioneira com efetiva participação sindical em sua gestão 7 .

O envolvimento da rede de saúde pública amplia-se, concretizando-se nos Programas de Saúde do Trabalhador (PST) criados na rede da SES de São Paulo (posteriormente em outros Estados) e implantados em várias regiões do estado a partir de 1985, em resposta à demanda do movimento sindical. Seu nome alia-se aos pressupostos que sustentam sua atuação. Tais pressupostos previam aspectos depois incorporados pelo SUS, tais como: a participação dos trabalhadores, em alguns casos na própria gestão, controle e avaliação; além do acesso às informações obtidas a partir do atendimento; possibilidade de desencadeamento de ações de vigilância nos locais de trabalho geradores de danos à saúde, com participação sindical; percepção do trabalhador como dono de um saber e como sujeito coletivo inserido no processo produtivo, agora visto não apenas como mero consumidor de serviços de saúde, de condutas, de prescrições, e a compreensão de que o processo de trabalho é danoso à saúde, ultrapassando o horizonte de visão da Saúde Ocupacional, o que aponta outras determinações para o sofrimento, o mal-estar e a doença, relacionados às relações sociais que se estabelecem nos processos de trabalho 7,25.

Assim, a proposta de políticas públicas influenciadas pelo campo Saúde do Trabalhador (juntamente com a Medicina Social Latino-Americana e a Saúde Coletiva) confere protagonismo aos serviços públicos de saúde no momento em que incorporam a atenção, integrando a assistência e a vigilância à saúde da população trabalhadora. Isso ocorre de forma programática, estabelecendo-se uma complexa rede de relações que incorpora a gestão participativa dos trabalhadores nos PST 7.

Saliente-se que os PST são uma tendência mundial, influenciada por organismos internacionais, que preconizam a incorporação de “ações de saúde (...) na rede de serviços de saúde pública" 32 (p. 2), conforme posição assumida pela OIT em 1985, quando propõe os Serviços de Saúde no Trabalho como política pública, com ampla participação dos trabalhadores, posição esta também defendida pela OMS. Eventos atestam a atuação da OMS, de forma mais clara, com o envolvimento do seu órgão regional para as Américas, a partir de 1983, ocasião em que a Organização Pan-Americana da Saúde (OPAS) publica o documento Programa de Salud de los Trabajadores 33. Em 1984, no seminário Actividades de Salud Ocupacional en la Red de Servi- 
cios de Salud patrocinado pela OPAS e realizado em Campinas, São Paulo, Brasil, documento de apoio às discussões elaborado por consultores do órgão colocava a necessidade de se “... passar do conceito de saúde ocupacional para o de saúde dos trabalhadores para enfrentar a problemática saúde-trabalho como um todo, onde se conjuguem fatores econômicos, culturais e individuais para que se possa produzir um resultado que é a saúde de uma sociedade, de um país, de um continente..." 34 (p. 47).

Existe, pois, internacionalmente, a preconização de abordagem que supere a visão da Saúde Ocupacional rumo à Saúde do Trabalhador, parte de uma tendência que coloca a saúde como direito 35.

Outros elementos da realidade brasileira ajudaram nas condições de emergência do discurso em Saúde do Trabalhador, contribuindo para sua efetivação como política de saúde, sendo identificados por alguns autores como espaços que permitiram a consolidação do campo Saúde do Trabalhador não somente do ponto de vista da formulação teórico-metodológica, como da prática em Saúde Pública. Tais elementos situamse na academia, mais particularmente, segundo Mendes 36, no Departamento de Saúde Ambiental, Faculdade de Saúde Pública, Universidade de São Paulo, e nos departamentos de medicina preventiva e social de algumas faculdades de medicina, sendo estes últimos os loci também apontados por Tambellini 37 .

Mendes 36 refere que essa realidade reflete a discussão internacional reveladora da falência dos serviços médicos de empresa como modelo hegemônico e baseado na Saúde Ocupacional. $\mathrm{O}$ autor enumera as razões que explicam tal falência, referindo-se particularmente à sua pouca credibilidade junto aos trabalhadores pela prática constante de não revelar resultados de exames, de manipular informações de saúde, de contribuir para a demissão dos não hígidos, de atuar no controle da força de trabalho. $\mathrm{Na}$ realidade brasileira, alia-se sua baixa cobertura porque, legalmente, são obrigatórios apenas nas maiores empresas.

Outro ator marcante, o movimento sindical de trabalhadores, também participa das mudanças e, segundo Mendes 36, a influência exercida sobre os sindicatos brasileiros pelo Modelo Operário Italiano (MOI) 38, a partir de final dos anos 1970, estimula a luta pela melhoria das condições de trabalho e defesa da saúde para superar o estágio economicista das reivindicações pelo recebimento dos adicionais de insalubridade, a “monetização do risco". Intercâmbio estabelecido entre técnicos, sindicalistas brasileiros e italianos, iniciado com a vinda de Giovani Berlinguer ao Brasil em 1978, ajuda a disseminar a proposta do MOI, método de intervenção contra a nocividade do trabalho desenvolvido pelos operários italianos, apoiados por técnicos militantes, no final dos anos 1960 19, sendo pilar importante na implantação do Sistema Nacional de Saúde como parte da Reforma Sanitária Italiana 39 e que terá influência sobre técnicos e dirigentes sindicais brasileiros atuantes em Saúde do Trabalhador.

O movimento pela Reforma Sanitária contribuiu para formular o projeto do SUS, conforme prescreveu a VIII Conferência Nacional de Saúde, de 1986, cujo relatório final apontava que o trabalho em condições dignas, o conhecimento e controle dos trabalhadores sobre processos e ambientes de trabalho, é um pré-requisito central para o pleno exercício do acesso à saúde 40 . A 1a Conferência Nacional de Saúde do Trabalhador incorpora a proposta do SUS, que deve englobar ações e órgãos de Saúde do Trabalhador, na perspectiva da saúde como direito, conforme tendência internacional de universalização do direito 35 .

Marcante na experiência histórica brasileira dentro da luta pela redemocratização, cujo ápice foi a Assembléia Constituinte, é a busca por direitos, quando os trabalhadores elegem o Estado como interlocutor, não na perspectiva da acumulação, numa visão meramente instrumental ou estrutural-funcionalista do seu papel, como pensavam estudiosos nos anos 1960-1970, conforme Fleury 41. Agora o Estado é um espaço de luta política pela incorporação dos direitos dos dominados, na perspectiva da construção de contra-hegemonia, ao planejar e executar políticas públicas que atendam às demandas sociais dos trabalhadores organizados, visando a implementar propostas de Saúde Pública que permitissem a gestão e seu controle social compartilhado, o que foi incorporado pelo SUS 7.

Os PST são resultado disso pois buscam retirar das empresas a tutela da saúde dos trabalhadores, dando-lhes o direito de exercer controle sobre a própria saúde, a partir da sua inserção nos serviços de saúde enquanto produtores, o que até o final dos anos 1970 e início dos 1980 não acontecia na assistência dada pelas empresas e pela Previdência Social através do Instituto Nacional de Assistência Médica da Previdência Social (INAMPS) 42 .

Assim, para se entender a emergência do campo Saúde do Trabalhador, como prática teórica (geração de conhecimentos) e prática político-ideológica (superação de relações de poder e conscientização dos trabalhadores), é necessário frisar que ele emerge concomitantemente à maturação do processo de industrialização e à forma particular que este assume na Améri- 
ca Latina, nos anos 1970, com o surgimento de uma classe operária industrial urbana. Esse ator que se conforma como força social e política, busca como aliados setores médios, particularmente intelectuais de fora e de dentro da universidade 7,37. As Semanas de Saúde do Trabalhador, realizadas a partir de 1979, espelham isso e resultam da ação conjunta de sindicatos de trabalhadores e de técnicos militantes. Dão origem à criação do DIESAT; à implantação de vários grupos de assessoria técnica nos sindicatos para questões relacionadas à saúde no trabalho, cujo fruto é a celebração de cláusulas nas negociações patronato e trabalhadores, relativas à melhoria das condições de trabalho e fortalecimento da representação nos locais de trabalho ?.

O protagonismo dos trabalhadores organizados, o envolvimento da rede de saúde pública nas ações de atenção à saúde (assistência + vigilância) que apreende as relações trabalho-saúde mediante a categoria processo de trabalho, constituem o cerne da abordagem em Saúde do Trabalhador, envolvendo "corações e mentes" resgatando o social para embasar saberes e práticas em saúde.

Um novo dado histórico é o fim dos milagres econômicos e a transformação do papel do Estado, com cortes nos gastos sociais, aumento do desemprego e subemprego, como decorrência da reestruturação produtiva - tecnológica e globalização da economia 43,44, com fortes influências sobre as lutas sindicais 5 .

Se a participação de 100 mil pessoas em todo país nas discussões preparatórias da 3 a Conferência Nacional de Saúde do Trabalhador pode representar um alento para os que militam no campo, a realidade vivida deve fazer pensar nos limites hoje existentes para um maior avanço das conquistas em Saúde do Trabalhador.

Ao se avaliar a situação dos protagonistas anteriormente assinalados, observa-se que se nos anos 1980, os PST contavam com importante participação/controle social, hoje, a fragilidade dos sindicatos de trabalhadores e a nova configuração do mundo do trabalho são fatores que dificultam esta participação, na medida em que os órgãos sindicais não mais representam o mundo do trabalho ${ }^{1}$. Ademais, a pujança observada na produção acadêmica na virada dos anos 1980-1990, cujo caráter interdisciplinar era evidente, ao lado da incorporação dos pressupostos do campo da Saúde do Trabalhador, particularmente no que se refere à contribuição dos autores filiados à Medicina Social Latino-Americana, conforme apontou Lacaz 7 , não mais é observada. Levantamento realizado por Mendes 2 relativo à produção de dissertações e teses sobre saúde e trabalho de 1950 até 2002, quando anali- sado sob a ótica da construção do conhecimento e da interdisciplinaridade, revelou “... o predomínio da construção de conhecimento fragmentado, (...) unidisciplinar, quando não repetitivo e tecnicista, resultante de pesquisas e análises pontuais desenvolvidas com abordagens próprias de cada disciplina: ou só da epidemiologia, ou (...) das ciências sociais e humanas, ou só da toxicologia, ou (...) engenharia ..." 1 (p. 802, grifo nosso).

Finalmente, no que se refere às resoluções emanadas da 3a Conferência Nacional de Saúde do Trabalhador ${ }^{6}$ que espelham o grau de formulação dos vários atores sociais envolvidos em Saúde do Trabalhador, pode-se observar que ao lado de forma geral ratificarem "enfaticamente" resoluções que apenas reiteram o tema central da 2a Conferência Nacional de Saúde do Trabalhador 45, realizada há 14 anos, em 1994, ou seja, o dístico Construindo uma Política [Nacional] de Saúde do Trabalhador, algumas resoluções expressam o retorno de propostas que "recuperam” as formulações da Saúde Ocupacional, desconsiderando inclusive o papel do SUS na saúde dos trabalhadores do setor público e o acúmulo desenvolvido em ações de Vigilância em Saúde do Trabalhador no SUS 46, as quais superam a prática da fiscalização do Ministério do Trabalho e Emprego, agora alçada à forma de atuação também do Ministério da Saúde. Essas observações podem ser vistas nas seguintes resoluções: "Eleger como prioridade de fiscalização, pelos Ministérios do Trabalho (...), da Saúde e do Meio Ambiente, o trabalho e as condições do desenvolvimento do trabalho ...", "garantir o cumprimento das normas regulamentadoras de segurança e saúde para os trabalhadores do serviço público, (...) priorizando o programa de prevenção de riscos ambientais e o programa de controle médico de saúde ocupacional"; "transformar os Serviços Especializados em Engenharia de Segurança e Medicina do Trabalho - SESMT (Norma Regulamentadora NR 4 do Ministério do Trabalho e Emprego) em serviços especializados de segurança e saúde no trabalho ..." 6 (Resolução no. ${ }^{\circ} 4$, grifos nossos). E, para expressar de forma clara a visão que orientou as resoluções, veja-se aquela que se dirige aos órgãos de fomento: "Priorizar a destinação de recursos das instituições de pesquisa para apoiar estudos das condições de trabalho, identificando os fatores determinantes e condicionantes dos agravos à saúde, visando a eliminar os riscos de acidentes (...) e doenças relacionadas ao trabalho, em decisão conjunta dos Ministérios da Saúde, da Previdência (...) e do Trabalho ..." 6 (Resolução no. 133, grifos nossos). Aqui cabe a indagação: Haveria formulação mais condizente com os pressupostos que embasam a Saúde Ocupacional? 
Percebe-se, que a fragilidade atual do movimento sindical, aliada à postura pouco engajada da academia e ao desenvolvimento de políticas públicas reducionistas, constrói um quadro de retrocesso no campo da Saúde do Trabalhador que é preciso combater, a partir do resgate dos pressupostos do campo e da crítica aos reducionismos perpretados pela Saúde Ocupacional, apesar de se observar, ainda, a hegemonia do seu discurso.

\section{Resumo}

O artigo discute pressupostos teórico-operacionais do campo Saúde do Trabalhador e os formulados pela Saúde Ocupacional. Refere-se às categorias teóricoconceituais que sustentam ambas as abordagens, visando a demonstrar as diferentes matrizes que as embasam e suas diferenças epistêmicas, considerando as formulações de Foucault relativas à Arqueologia. Justifica-se tal empreitada pela constatação de que a abordagem interdisciplinar que caracterizou as pesquisas em Saúde do Trabalhador está sendo abandonada, ao lado da involução programática das ações de Saúde Pública em nível das políticas sociais, da fragilidade do movimento sindical e dos equívocos conceituais ob- servados no Relatório Final da 3 a Conferência Nacional de Saúde do Trabalhador realizada em novembro de 2005 e convocada pelos Ministérios da Previdência Social, da Saúde e do Trabalho e Emprego. Tal evento representou o resultado das Conferências de Saúde do Trabalhador realizadas nos Estados e municípios, que mobilizaram cerca de 100 mil militantes pelo Brasil, representados pelos delegados a $3 \underline{a}$ Conferência Nacional de Saúde do Trabalhador.

Saúde do Trabalhador; Política de Saúde do Trabalhador; Conhecimentos, Atitudes e Prática em Saúde 


\section{Referências}

1. Gomez CM, Lacaz FAC. Saúde do trabalhador: novas-velhas questões. Ciênc Saúde Coletiva 2005; 10:797-807.

2. Mendes R. Produção científica brasileira sobre saúde e trabalho publicada na forma de dissertações de Mestrado e teses de Doutorado, 19502002. Revista Brasileira de Medicina do Trabalho 2003; 2:87-118.

3. Ministério da Saúde. Portaria no ${ }^{\circ}$ 1.679/GM. Dispõe sobre a Rede Nacional de Atenção Integral à Saúde do Trabalhador (RENAST). Diário Oficial da União 2002; 19 set.

4. Hoefel MG, Dias EC, Silva JM. A atenção à saúde do trabalhador no SUS: a proposta de constituição da RENAST. Brasília: Ministério da Saúde/Ministério do Trabalho e Emprego/Ministério da Previdência e Assistência Social; 2005.

5. Steingart G. Uma baixa causada pela globalização: a morte dos sindicatos. Der Spiegel 2006; 28 out.

6. Ministério da Saúde. Resoluções da 3a. Conferência Nacional de Saúde do Trabalhador; 2006. http:// www.anamt.org.br/downloads/relatorio_final_ CNST_24_03_06.pdf (acessado em 07/Nov/2006).

7. Lacaz FAC. Saúde do trabalhador: um estudo sobre as formações discursivas da academia, dos serviços e do movimento sindical [Tese de Doutorado]. Campinas: Faculdade de Ciências Médicas, Universidade Estadual de Campinas; 1996.

8. Laurell AC. Saúde e trabalho: os enfoques teóricos. In: Nunes ED, organizador. As ciências sociais em saúde na América Latina: tendências e perspectivas. Brasília: Organização Pan-Americana da Saúde; 1985. p. 255-76.

9. Gomez CM, Thedim-Costa SMF. Incorporação das ciências sociais na produção de conhecimento sobre trabalho e saúde. Ciênc Saúde Coletiva 2003; 8:125-36.

10. Tambellini AT. O trabalho e a doença. In: Guimarães $\mathrm{R}$, organizador. Saúde e medicina no Brasil: contribuição para um debate. Rio de Janeiro: Edições Graal; 1978. p. 93-119.

11. Laurell AC, coordinadora. Para la investigación sobre la salud de los trabajadores. Washington DC: Organización Panamericana de la Salud; 1993.

12. Laurell AC, Noriega M. Processo de produção e saúde: o desgaste operário. Rio de Janeiro: Centro Brasileiro de Estudos de Saúde/São Paulo: Editora Hucitec; 1989.

13. Tambellini AT, Porto MFS, Galvão LAC, Machado JMH. Política Nacional de Saúde do Trabalhador: análises e perspectivas. Rio de Janeiro: Centro de Estudos da Saúde do Trabalhador e Ecologia Humana, Escola Nacional de Saúde Pública Sergio Arouca, Fundação Oswaldo Cruz; 1986.

14 Foucault M. A arqueologia do saber. Rio de Janeiro: Editora Forense Universitária; 1987.

15. Foucault M. Verdade e poder. In: Foucault M, Machado R, organizadores. Microfísica do poder. Rio de Janeiro: Edições Graal; 1982. p. 1-14.

16. Adorno S. Introdução: um pensamento desconcertante. In: Adorno S, organizador. Michel Foucault - escritos. Rio de Janeiro: Editora Forense Universitária; 1994. p. i-xii.
17. Rodrigues IJ. O sindicalismo brasileiro: da confrontação à cooperação conflitiva. São Paulo Perspect 1995; 9:116-26.

18. Mendes R, organizador. Medicina do trabalho: doenças profissionais. Rio de Janeiro: Editora Sarvier; 1980.

19. Oddone I, Marri G, Gloria S, Briante, Chiattella M, Re A. A luta dos trabalhadores pela saúde. Rio de Janeiro: Centro Brasileiro de Estudos de Saúde/ São Paulo: Editora Hucitec; 1986.

20. Robin R. História e lingüística. São Paulo: Editora Cultrix; 1977.

21. Arouca ASS. O dilema preventivista: contribuição para a compreensão e crítica da medicina preventiva [Tese de Doutorado]. Campinas: Faculdade de Ciências Médicas, Universidade Estadual de Campinas, 1975.

22. Dejours CH. A loucura do trabalho: estudo de psicopatologia do trabalho. São Paulo: Editora Oboré; 1987.

23. Araújo A, Alberto MF, Neves MY, Athayde M, organizadores. Cenários do trabalho: subjetividade, movimento e enigma. Rio de Janeiro: DP\&A Editora; 2004.

24. Marx K. Processo de trabalho e processo de produzir mais valia. In: Marx K, organizador. O capital: crítica da economia política. Livro primeiro: o processo de produção do Capital. v. I. Rio de Janeiro: Editora Civilização Brasileira; 1980. p. 201-23.

25. Navarro V. The labour process and health: a historical materialist interpretation. Int J Health Services 1982; 12: 5-29.

26. Teixeira SMF, Oliveira JA. Medicina de grupo: a medicina e a fábrica. In: Guimarães R, organizador. Saúde e medicina no Brasil: contribuição para um debate. Rio de Janeiro: Edições Graal; 1978. p. 181-206.

27. Foucault M. Vigiar e punir: nascimento da prisão. Petrópolis: Editora Vozes; 1994.

28. Laurell AC. Medicina y capitalismo en México. Cuadernos Políticos 1975; 5:6-16.

29. Mendes R, organizador. Patologia do trabalho. Rio de Janeiro: Editora Atheneu; 1995.

30. Singer PI. A crise do "milagre": interpretação crítica da economia brasileira. Rio de Janeiro: Editora Paz \& Terra; 1976.

31. Parmegiani L. Occuppational health services in 1984: a prospective model. Am J Ind Med 1985; 7:91-2.

32. Organización Internacional del Trabajo. Convención 161: servicios de salud en el trabajo. Geneva: Organización Internacional del Trabajo; 1985.

33. Organización Panamericana de la Salud. Programa de Salud de los Trabajadores: ante-projeto. Washington DC: Organización Panamericana de la Salud; 1983.

34. Sandoval HO. Actividades de salud ocupacional en la red de servicios de salud - marco conceptual. In: Seminario Actividades de Salud Ocupacional en la Red de Servicios de Salud. Washington DC: Organización Panamericana de la Salud/Organización Mundial de la Salud; 1984. p. 1-29. 
35. Parmeggiani L. Evolução dos conceitos e práticas de medicina do trabalho. Saúde \& Trabalho 1988; 2:3-13.

36. Mendes R. Doutrina e prática da integração da saúde ocupacional no setor saúde: contribuição para a definição de uma política [Tese de Livre Docência]. São Paulo: Faculdade de Saúde Pública, Universidade de São Paulo; 1986.

37. Tambellini AT. A política oficial de desenvolvimento científico e tecnológico no Brasil na área de saúde e trabalho: discurso e prática. In: ABRASCO, organizador. Ensino da saúde publica, medicina preventiva e social no Brasil. Rio de Janeiro: ABRASCO; 1984.

38. Berlinguer G. Medicina e política. Rio de Janeiro: Centro Brasileiro de Estudos de Saúde/São Paulo: Editora Hucitec; 1978.

39. Berlinguer G, Teixeira SF, Campos GWS. Reforma sanitária: Itália e Brasil. Rio de Janeiro: Centro Brasileiro de Estudos de Saúde/São Paulo: Editora Hucitec; 1988.

40. Ministério da Saúde. VIII Conferência Nacional de Saúde - relatório final. Brasília: Ministério da Saúde; 1986.
41. Fleury S. Estado sem cidadãos: seguridade social na América Latina. Rio de Janeiro: Editora Fiocruz; 1994.

42. Dias EC. A atenção à saúde dos trabalhadores no setor saúde (SUS), no Brasil: realidade, fantasia ou utopia? [Tese de Doutorado]. Campinas: Faculdade de Ciências Médicas, Universidade Estadual de Campinas; 1994.

43. Antunes R. Adeus ao trabalho? Ensaio sobre as metamorfoses e a centralidade do mundo do trabalho. São Paulo: Cortez Editora/Campinas: Editora da Universidade Estadual de Campinas; 1995.

44. Antunes R. A nova morfologia do trabalho e o desenho multifacetado das ações coletivas. Cadernos ANDES 2005; 21:8-16.

45. Ministério da Saúde. Anais da 2a Conferência Nacional de Saúde do Trabalhador 1994. Brasília: Ministério da Saúde; 2002.

46. Porto MFS, Lacaz FAC, Machado JMH. Promoção da saúde e intersetorialidade: contribuições e limites da vigilância em saúde do trabalhador no Sistema Único de Saúde. Saúde Debate 2003; 27:192-203.

Recebido em 03/Abr/2006

Versão final reapresentada em 21/Nov/2006

Aprovado em 11/Jan/2007 